\title{
Influence of ammonium nitrate on larval anti-predatory responses of two amphibian species
}

\author{
Manuel E. Ortiz-Santaliestra ${ }^{\mathrm{a}, *}$, María José Fernández-Benéitez ${ }^{\mathrm{a}}$, Adolfo Marco ${ }^{\mathrm{b}}$, Miguel Lizana $^{\mathrm{a}}$ \\ ${ }^{\text {a }}$ Universidad de Salamanca, Departamento de Biología Animal, Campus Unamuno, 37007 Salamanca, Spain \\ Estación Biológica de Doñana CSIC, C/Américo Vespucio s/n, 41092 Sevilla, Spain
}

Keywords:

Behavioural toxicology

Fertilizers

Multiple stressors

Predation

Sublethal effects

\begin{abstract}
a b s t r a c t
Sublethal effects of toxicants can upset normal behavioural responses to predators, leading to increased predation. For example, sensory capabilities can be impaired by toxicants, leading to difficulty in detecting predators or other threats. Alteration of locomotor abilities by pollutants can also explain the difficulty of tadpoles to escape from predators. Here we assess the effects of a nitrogenous fertilizer on the response to predators shown by anuran tadpoles. In a first experiment, we chronically exposed Iberian painted frog (Discoglossus galganoi) and spadefoot toad (Pelobates cultripes) tadpoles to environmentally relevant concentrations of ammonium nitrate. After the exposure, we tested tadpoles' ability to avoid predation by the red crayfish (Procambarus clarkii). In a second experiment, we analysed the escape behaviour of P. cultripes tadpoles as a function of ammonium nitrate exposure and presence of predatory crayfishes. Tadpoles of both species that were exposed to ammonium nitrate were consumed by crayfishes faster than controls (mean time of predation: Dg controls $=18.03 \mathrm{~h}, 90.3 \mathrm{mg} \mathrm{N}-\mathrm{NO}_{3} \mathrm{NH}_{4} / \mathrm{L}=7.48 \mathrm{~h}$; Pc controls $=16.12 \mathrm{~h}$, $90.3 \mathrm{mg} \mathrm{N}-\mathrm{NO}_{3} \mathrm{NH}_{4} / \mathrm{L}=9.46 \mathrm{~h}$ ). Control larval P. cultripes showed specific anti-predator escape responses, whereas those exposed to the fertilizer did not. We demonstrate, for the first time in amphibians, how nitrogenous fertilizers can affect larval defensive behaviours, and thereby increase the risk of predation. Our results emphasize the importance of considering environmental stresses on the ecotoxicological studies with amphibians.
\end{abstract}

\section{Introduction}

Like many other organisms, amphibian larvae must face a tradeoff between foraging and predator avoidance, since the search for food is usually associated with an increased predation (Bridges, 2002). Active foraging is related to a larger size at metamorphosis and therefore to a higher reproductive success and survival probability during the terrestrial stages (Smith, 1987). However, the probability of predation is also higher as feeding activity increases (Skelly, 1992). Selective pressures should then lead the animals to maximise the efficiency of feeding behaviour while minimising the exposure to predators. When exposed to predator cues, some tadpoles remain motionless or increase refuge use (Babbitt and Tanner, 1997; Fraker, 2008; Lefcort, 1996), while foraging is more frequent when predator signals are absent (Sih, 1992). Nevertheless, some environmental stressors such as ultraviolet radiation, pathogens or chemical pollutants can impair these tad-

\footnotetext{
* Corresponding author. Present address: Instituto de Investigación en Recursos Cinegéticos UCLM-CSIC-JCCM, Ronda de Toledo s/n, 13071 Ciudad Real, Spain. Tel.: +34926 295450; fax: +34926295451.

E-mail address: ManuelE.Ortiz@uclm.es (M.E. Ortiz-Santaliestra).
}

pole behavioural responses, thus leading to increased predation risks (Kats et al., 2000; Lefcort and Blaustein, 1995; Parris et al., 2004).

Tadpoles recognize predators mainly through chemical cues (Kiesecker et al., 1999; Peacor, 2006). For example, tadpoles can distinguish among different predators and produce predator-specific cues (i.e., kairomones) which are supposed to be linked to the riskiness and the hunting strategy of the predator (Relyea, 2001; Schoeppner and Relyea, 2009). In addition, prey species release prey-specific cues (i.e., alarm cues), which may be used by congeners to recognize predator's diet (Schoeppner and Relyea, 2005, 2009). The use of visual cues is usually very restricted as a consequence of the characteristics of tadpole environments, where vegetation, high turbidity and suspended organic matter limit the visibility (Kiesecker et al., 1996; Petranka et al., 1987). The chemicals present in the environment can impair the chemosensory system of tadpoles by, for example, provoking necrotic death of all the cell types present in the olfactory epithelium (Yovanovich et al., 2009).

The impairment of the chemosensory system may indirectly reduce the ability of tadpoles to detect predators. Lefcort et al. (1998) demonstrated that Rana luteiventris tadpoles exposed in the laboratory to environmentally relevant levels of zinc (15 ppm) and 

lead (5 ppm) did not show a normal escape response to chemical cues emanating from predacious rainbow trout. Furthermore, the exposure to pollutants is known to affect the activity of tadpoles. Raimondo et al. (1998) observed experimentally a lower swimming activity of Rana catesbeiana tadpoles collected from a coal ash polluted area than in those collected from a reference site. All these behavioural effects can lead to increased predation risk of tadpoles exposed to environmental contaminants. For example, larval Ambystoma macrodactylum hatched from eggs exposed to ecologically realistic concentrations of methoxychlor showed a mean latency to ingestion by predators significantly lower that controls (Verrell, 2000).

Ammonium nitrate is one of the most commonly used fertilizers worldwide and its application on crop fields has increased in parallel with the use of inorganic nitrogenous fertilizers. Excess ammonium nitrate flows via runoff into nearby water bodies, where nitrogen concentrations may reach levels harmful for aquatic wildlife (Vitousek et al., 1997). Ammonium nitrate is known to produce deleterious effects on anuran tadpoles, including increased mortality, anatomical abnormalities and delayed growth and development (e.g., Ortiz et al., 2004). Exposure to ammonium nitrate has been shown to reduce activity or feeding rate in a variety of amphibian larvae (Burgett et al., 2007; Hecnar, 1995; Xu and Oldham, 1997). Several mechanisms have been suggested to explain ammonia and nitrate toxicity (see review by Marco and Ortiz-Santaliestra, 2009). Exposure of tadpoles to moderate levels of ammonia can cause a reversion in the ammonia diffusion gradient and animals can take up ammonia from the water. In these cases, the energetically costly urea synthesis becomes a common mechanism of detoxifying ammonia (Wright and Wright, 1996). This additional energetic investment may result in reduced growth and activity as well as affect the general fitness. On the other hand, nitrate may be reduced to nitrite in the large bowel; then, nitrite enters the bloodstream, where it reacts with haemoglobin, thus producing methaemoglobin and reducing the oxygen-carrying capacity of the red blood cells. The initial stages of nitrite intoxication may therefore include a reduction in respiratory efficiency, thus affecting the activity of the organism. However, nothing is known about the impact of this reduced activity on larval susceptibility to predation.

Un-ionized ammonia, the more toxic form of ammonia, produces a decrease in glutamate, a potential neurotransmitter, in the brain of some animals (Vedel et al., 1998). Although this neurotoxic effect has not been analysed in amphibians so far, it might ultimately affect the behavioural response of tadpoles against predators. In the only study we are aware of that combined exposures of amphibian tadpoles to inorganic nitrogen and predator chemical cues, Burgett et al. (2007) did not find any effect of ammonium nitrate on the specific anti-predatory behaviour of larval Rana sylvatica. However, they did not conduct a predator challenge to test the whether the reduced activity of fertilizer-exposed tadpoles affected predation rate.

The aim of the present study is to analyse how the exposure to environmentally relevant levels of ammonium nitrate affects the ability of tadpoles to avoid predation. In order to meet this goal, we designed predation challenges for tadpoles of Iberian painted frog (Discoglossus galganoi) and spadefoot toad (Pelobates cultripes). Additionally, P. cultripes larval behaviour as a function of the ammonium nitrate exposure and predator presence was studied. Both species are common in agricultural areas from Central and Southern Iberian Peninsula (Martínez-Solano, 2009; Recuero, 2010), where they breed in temporary ponds susceptible to receive high inputs of inorganic nitrogen from fertilizer runoff. Previous ecotoxicological studies have shown that embryos and hatchlings of these two species experience higher mortality and slower growth rates than free swimming larvae when exposed to environmentally relevant levels of ammonium nitrate (Ortiz-Santaliestra et al., 2006). However, increased larval mortality might happen as a consequence of a potential alteration of anti-predatory responses.

\section{Materials and methods}

\subsection{Sample collection and exposure to ammonium nitrate}

We collected approximately 200 D. galganoi eggs from three different clutches and 300 P. cultripes eggs from five clutches in November 2002 in Doñ ana National Park (Almonte, Huelva, SW Spain). Eggs were collected by dip netting when they were at Gosner stage 13 (Gosner, 1960) and transported to the laboratory where clutches were kept separately in aquaria with $3 \mathrm{~L}$ of dechlorinated water and allowed to develop at $20^{\circ} \mathrm{C}$ and the natural photoperiod. Once tadpoles reached Gosner stage 24 (when the operculum closes) either 15 individuals of D. galganoi (five per clutch) or 20 individuals of P. cultripes (four per clutch) were transferred into new aquaria with $10 \mathrm{~L}$ of dechlorinated water. Nitrate concentrations in the ponds of origin varied from 1.69 to $2.26 \mathrm{mg} \mathrm{N}-\mathrm{NO}_{3}{ }^{-} / \mathrm{L}$, whereas ammonium varied from 0.23 to $0.39 \mathrm{mg} \mathrm{N}-\mathrm{NH}_{4}{ }^{+} / \mathrm{L}$. We used individuals from these ponds with low nitrogen charge to avoid possible phenomena of local adaptation by individuals to water pollution. All the surviving tadpoles that were not used in the experiments were released in the same place where they were collected.

We randomly assigned each aquarium to a specific ammonium nitrate level and replicated each level three times. In the D. galganoi experiment we used four nominal ammonium nitrate concentrations $\left(0,22.6,45.2\right.$ and $\left.90.3 \mathrm{mg} \mathrm{N}-\mathrm{NO}_{3} \mathrm{NH}_{4} / \mathrm{L}\right)$. These concentrations are consistent with the levels expected in the amphibian breeding ponds located in agricultural environments just after the drainage of fertilizers by rains (Egea-Serrano et al., 2008; Ortiz-Santaliestra et al., 2006; Scholefield et al., 1996). Exposure lasted for 15 days. During the whole exposure phase, tadpoles were fed ad libitum with lettuce that was boiled during $5 \mathrm{~min}$ and then rinsed with dechlorinated water. We renewed the water and readjusted the nominal concentrations at days 5 and 10 of exposure. For P. cultripes, we used only one experimental ammonium nitrate concentration (90.3 $\mathrm{mg} \mathrm{N}-\mathrm{NO}_{3} \mathrm{NH}_{4} / \mathrm{L}$ ) as well as a control treatment. Each treatment was replicated five times. This exposure lasted for 12 days, and water was changed and nominal level readjusted every 4 days. The duration of the exposure phase was determined on the basis of previous experiments; according to the sensitivity showed by tadpoles of both species (Ortiz-Santaliestra et al., 2006), we established each specific period to get a sublethal exposure appropriate to test the anti-predatory responses defined in the objective. The number of experimental concentrations used for each species was dependent on the sample size, which was determined by the conditions of the collection permits and by the number of clutches found in the field.

For both species, we prepared a stock solution with ammonium nitrate salt (99\% pure; Merck, Darmstaad, Germany) and pipetted the corresponding volumes of this solution into the experimental tanks to get the nominal ammonium nitrate concentrations. We analysed ammonium and nitrate levels before each water change with colorimetric tests (Visocolor, Macherey-Nagel, Düren, Germany). The maximum variation respect the nominal level was below $10 \%$ in all cases.

Water $\mathrm{pH}$ throughout the experiments varied between 7.20 and $7.40 \mathrm{pH}$ meter Hanna HI-8314Nt, Hanna Instruments Spain, Eibar, Spain). Dissolved oxygen levels ranged from 6.03 to $7.10 \mathrm{mg} / \mathrm{L}$ (Oximeter Handylab OX1/Sett, Schott-Geräte, Hofheim, Germany). 
Total hardness of the test water was measured by titration (Visocolor, Macherey-Nagel, Düren, Germany) and varied between 0.89 and $1.07 \mathrm{mmol} / \mathrm{L}$. Ammonium nitrate concentration did not affect any of these parameters ( $p>0.05$ in all cases). We did not measure water salinity, which could be though to be affected by the addition of the ammonium nitrate salt because, in a recent study, we observed that the maximum levels used in the present work did not affect water salinity significantly (Ortiz-Santaliestra et al., 2010).

At the end of the exposure to ammonium nitrate, we recorded the survival rate in each tank and the total length of each animal (mouth to tip of the tail) with a digital calliper (Acha S.L., Eibar, Spain) to the nearest $0.01 \mathrm{~mm}$. All procedures were performed in compliance with relevant laws and institutional guidelines; the Ministry of Environment of Spain issued the corresponding permits for animal collection and experimentation (Doñana NP project 24/2002).

\subsection{Predation challenge}

At the end of the exposure period, we randomly selected five D. galganoi tadpoles or seven P. cultripes tadpoles in each aquarium for the predation challenge. Tadpoles from each aquarium of the exposure phase were kept together in a new aquarium with $3 \mathrm{~L}$ dechlorinated water without ammonium nitrate for the predation challenge; thus, we kept the same treatments and replicates as during the exposure phase. We introduced into each aquarium a single red crayfish (Procambarus clarkii) that acted as predator. The red crayfish is an exotic species in the region, and its predation on amphibian eggs and larvae has already been demonstrated (Cruz et al., 2006). It is very abundant in almost all the water bodies in the area of origin of the tadpoles used in the present study. We collected 100 crayfishes from the same ponds of origin of the amphibians used in the experiment. Then, we selected 22 out of this 100 among those showing a similar size (mean size $\pm \mathrm{SE}=71.80 \pm 0.16 \mathrm{~mm}$ ). Each selected crayfish was randomly assigned to one of the aquaria used in the predation challenges (12 aquaria in the D. galganoi experiment and 10 aquaria in the P. cultripes experiment). Since our objective was not to assess the influence of the ammonium nitrate on the predator-prey relationships, but to use the larval anti-predatory skills as a new endpoint to analyse the toxicity of the fertilizer, we did not expose the crayfishes to the chemical.

The experiment began within the hour following the end of the exposure phase, at the moment that crayfishes were introduced into the aquaria, and lasted for $14 \mathrm{~h}$. Due to the effects of ammonium nitrate on tadpole growth rates, there were differences among aquaria in the size of tadpoles at the beginning of the predation challenges. These differences are presented below. We counted the number of tadpoles eaten each hour and calculated the predation rates as the number of tadpoles eaten divided by the number of initial tadpoles in the aquarium.

We analysed the effects of ammonium nitrate on larval susceptibility to predation with repeated measures analyses of variance (ANOVAs), with the increase of larval predation rates over time as dependent variables. When statistically significant differences were detected, we used hourly one-way ANOVAs with the predation rates per aquarium (arcsin of square root transformed) as dependent variable to know at what specific times of exposure these differences occurred. In the D. galganoi experiment, we used Tukey post hoc tests to know which specific ammonium nitrate concentration caused significant effects on the predation rate. We checked the influence of larval size on predation rate with repeated measures analyses of covariance (ANCOVAs) using the mean larval length (log transformed) per aquarium as a covariate. Finally, we obtained the mean time of predation (or time at

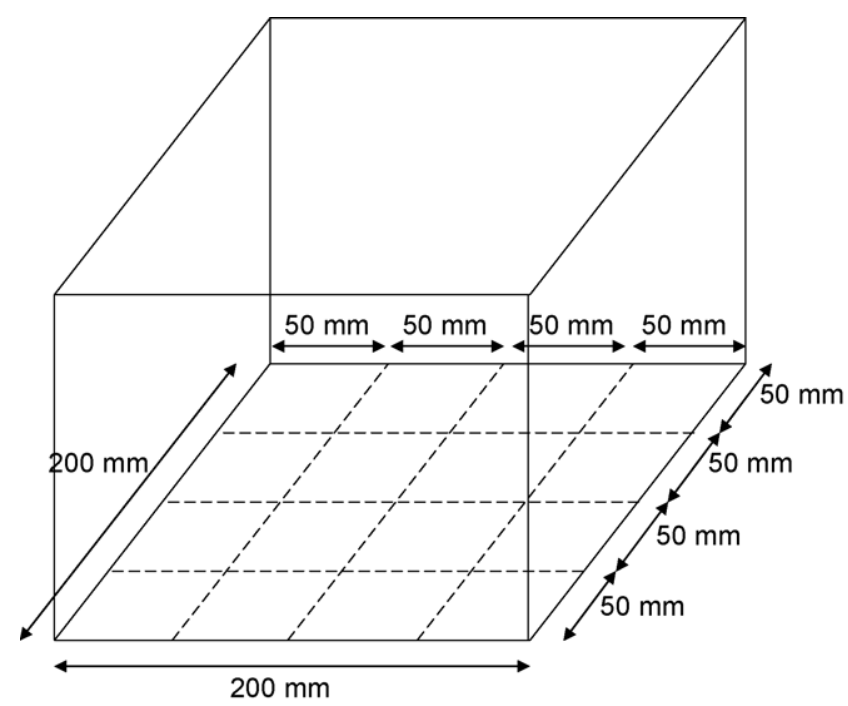

Fig. 1. Behaviour experiment aquarium. Illustration of one of the aquaria where the behaviour experiment was carried out. The three dashed lines in each direction on the bottom of the tanks were used to estimate the activity of Pelobates cultripes tadpoles as a function of the ammonium nitrate and predator treatments.

which half of the individuals were eaten) with a probit regression.

\subsection{Behaviour experiment}

We repeated the exposure phase with P. cultripes eggs collected in December 2002 from the same site as above. We used the same design as in the previous experiment. After the end of the exposure phase, survivors from all the aquaria of the same treatment (control or $90.3 \mathrm{mg} \mathrm{N}-\mathrm{NO}_{3} \mathrm{NH}_{4} / \mathrm{L}$ ) were put together in tanks with $20 \mathrm{~L}$ of dechlorinated water. Then, we randomly selected 60 tadpoles that were distributed into six aquaria (10 tadpoles per aquarium) with $3 \mathrm{~L}$ of dechlorinated water. These aquaria had a square-shaped base with a side length of $200 \mathrm{~mm}$. On the bottom of each tank and parallel to the borders, we drew three lines in each direction in such way that each line was $50 \mathrm{~mm}$ away from the adjacent line or from the aquarium border (Fig. 1). Inside each aquarium we introduced a cylindrical fishnet cage (80 $\mathrm{mm}$ diameter, $100 \mathrm{~mm}$ height), with open ends, whose top part remained out of the water. The net had a hole size of $5 \mathrm{~mm}$, small enough to prevent tadpoles from swimming into it. In three of the six aquaria of each treatment, we introduced a crayfish into the cages through the open emerged end, while the cages in the other three aquaria remained empty. Fifteen minutes after introducing the crayfishes, we applied a stimulus that consisted in the sudden lifting of the cage in such way that crayfishes, where present, were released. We recorded what happened in each aquarium after stimuli application with a Handycam Digital 8 video camera (Model DCR-TRV355E; Sony, Tokyo, Japan). We then observed the videotapes and estimated the swimming activity of tadpoles as a function of two variables: the number of times that any of the lines was crossed and the mean time that tadpoles spent swimming after the stimulus. The crayfishes were removed from the aquaria once all the tadpoles stopped swimming in order to avoid tadpole consumption. In each aquarium we repeated this trial four times, with $3 \mathrm{~h}$ of separation among trials, and obtained an average value per aquarium for each variable.

Both the number of times that lines were crossed and the swimming time were log transformed. To analyse the effects of ammonium nitrate and predator presence on these variables we used two-way ANOVAs. SPSS 11.5 for Windows (SPSS Inc., Chicago, IL, USA) was used for statistical analyses. 
Table 1

Results of the repeated measures analyses of the covariance (ANCOVAs) to test the influence of larval length on predation rates of Discoglossus galganoi and Pelobates cultripes tadpoles exposed to different levels of ammonium nitrate.

\begin{tabular}{llllll}
\hline Species & Source of variation & Sum of squares & df & F & p \\
\hline \multirow{2}{*}{ D. galganoi } & Length & 0.355 & 1 & 0.307 & 0.597 \\
& Ammonium nitrate & 2.875 & 3 & 0.828 & 0.519 \\
& Error & 8.104 & 7 & & \\
P. cultripes & Length & 0.515 & 1 & 1.106 & 0.328 \\
& Ammonium nitrate & 3.286 & 1 & 7.066 & 0.033 \\
& Error & 3.255 & 7 & & \\
\hline
\end{tabular}

\section{Results}

\subsection{Predation challenge}

Mortality during the exposure phase was below $10 \%$ in all experiments and ammonium nitrate treatments. However, the fertilizer affected the growth rate in both species, so the individuals from different treatments showed different sizes when predation challenge began. The mean lengths of $\mathrm{D}$. galganoi tadpoles after exposure to 22.6, 45.2 and $90.3 \mathrm{mg} \mathrm{N}-\mathrm{NO}_{3} \mathrm{NH}_{4} / \mathrm{L}$ were, respectively, $13.91 \pm 0.76, \quad 12.40 \pm 0.73$ and $9.95 \pm 0.06 \mathrm{~mm}$, while controls showed a final length of $14.37 \pm 0.22 \mathrm{~mm}\left(\mathrm{~F}_{3,8}=49.607, \mathrm{p}<0.001\right)$. Regarding P. cultripes, total lengths after the 15 days of exposure period were $12.86 \pm 0.73 \mathrm{~mm}$ in controls and $11.50 \pm 0.58 \mathrm{~mm}$ in the individuals exposed to the ammonium nitrate $\left(\mathrm{F}_{1,8}=11.005\right.$, $\mathrm{p}=0.011$ ).

During the predation challenges, no larval mortality by causes other than predation was observed and no wounded or partially eaten tadpoles were observed at any time. The predation rate of D. galganoi tadpoles increased with the concentration of ammonium nitrate to which individuals had been exposed as revealed by the repeated measures ANOVA $\left(\mathrm{F}_{3,8}=4.355, \mathrm{p}=0.043\right)$. Seven hours after the introduction of the crayfishes into the aquaria, none of the controls had been eaten while predation rate of the individuals previously exposed to the highest ammonium nitrate concentration was $46.7 \%\left(\mathrm{~F}_{3,8}=4.156, \mathrm{p}=0.048\right)$. At the end of the experiment $(14 \mathrm{~h})$ survival rates per treatment were $93.3 \pm 6.7 \%$ in the controls, $73.3 \pm 13.3 \%$ at $22.6 \mathrm{mg} \mathrm{N}-\mathrm{NO}_{3} \mathrm{NH}_{4} / \mathrm{L}$, $53.3 \pm 24.0 \%$ at $45.2 \mathrm{mg} \mathrm{N}-\mathrm{NO}_{3} \mathrm{NH}_{4} / \mathrm{L}$, and $13.3 \pm 6.7 \%$ at $90.3 \mathrm{mg} \mathrm{N}-$ $\mathrm{NO}_{3} \mathrm{NH}_{4} / \mathrm{L}$ (Fig. 2a). In spite of these differences, post hoc tests revealed that only at the highest treatment the predation rate was significantly higher than that of the controls. When we considered the mean larval size as a covariate, no differences among treatments in the evolution of predation rates over time were detected (Table 1 ). The mean times of predation per treatment, including their 95\% confidence intervals, were $18.04 \mathrm{~h}$ in the controls, $17.35(14.20-26.28) \mathrm{h}$ at $22.6 \mathrm{mg} \mathrm{N}-\mathrm{NO}_{3} \mathrm{NH}_{4} / \mathrm{L}, 13.68$ (10.22-33.44) h at $45.2 \mathrm{mg} \mathrm{N}-\mathrm{NO}_{3} \mathrm{NH}_{4} / \mathrm{L}$, and $7.48(6.45-8.52) \mathrm{h}$ at $90.3 \mathrm{mg} \mathrm{N}-\mathrm{NO}_{3} \mathrm{NH}_{4} / \mathrm{L}$. Confidence interval could not be calculated for the control treatment because the predation rate was null in two of the three replicates.

As with D. galganoi, the repeated measures ANOVA revealed that the previous exposure to ammonium nitrate increased the rate at which $P$. cultripes tadpoles were predated by crayfishes $\left(F_{1,10}=6.138, p=0.006\right)$ although in this case the effect of the fertilizer on susceptibility to predation was not size-dependent (Table 1). After $10 \mathrm{~h}$ of introduction of the crayfishes, predation rates were $22.8 \%$ in the controls and $74.3 \%$ at $90.3 \mathrm{mg} \mathrm{N}-\mathrm{NO}_{3} \mathrm{NH}_{4} / \mathrm{L}$ $\left(F_{1,8}=7.454, p=0.026\right)$. At the end of the experiment, these values were $28.6 \%$ for the controls and $82.9 \%$ for the tadpoles previously exposed to the fertilizer (Fig. 2b). In the case of P. cultripes, however, the negative effect of the ammonium nitrate on susceptibility to predation remained after size correction (Table 1). Finally, mean

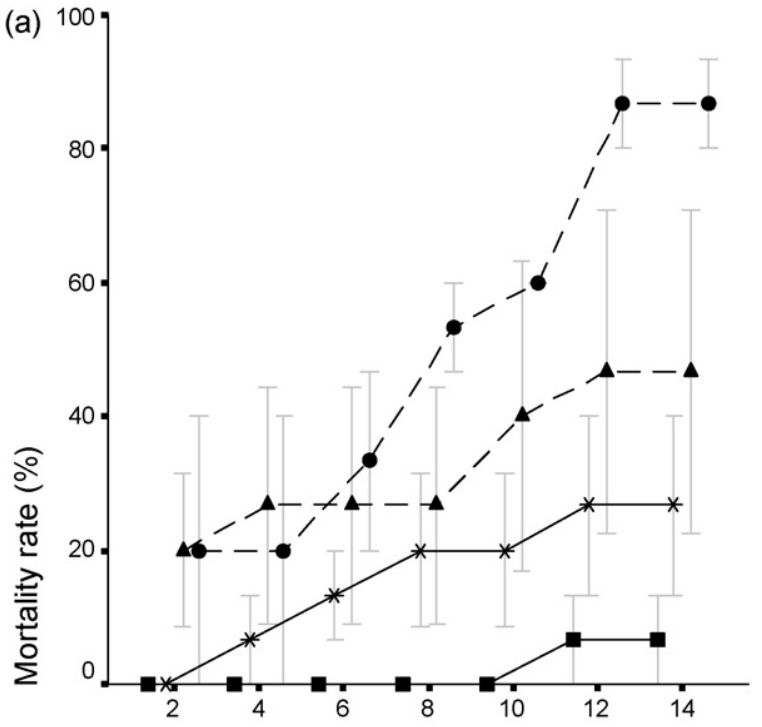

Time (hours)

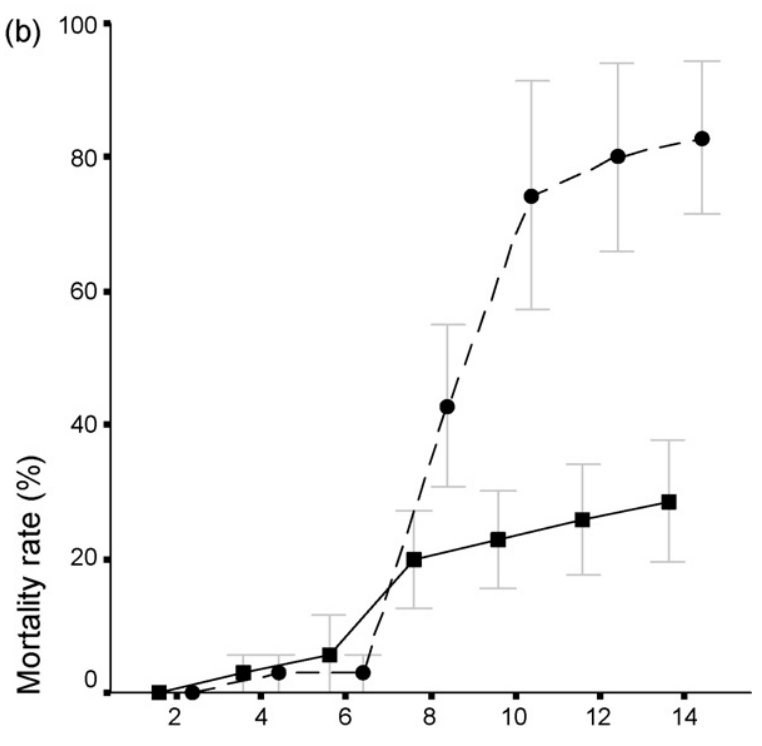

Time (hours)

Fig. 2. Predation rates. Evolution of the predation rates of tadpoles of two amphibian species exposed to different levels of ammonium nitrate. Continuous lines with square markers correspond to control tadpoles, continuous lines with asterisks to tadpoles exposed to $22.6 \mathrm{mg} \mathrm{N} / \mathrm{L}$, dashed lines with triangles to tadpoles exposed to $45.2 \mathrm{mg} \mathrm{N} / \mathrm{L}$ and dashed lines with circles to tadpoles exposed to $90.3 \mathrm{mg} \mathrm{N} / \mathrm{L}$. (a) Discoglossus galganoi experiment and (b) Pelobates cultripes experiment.

times of predation in this species were $16.12(14.36-19.17) \mathrm{h}$ in the controls and $9.46(8.77-10.19)$ at $90.3 \mathrm{mg} \mathrm{N}-\mathrm{NO}_{3} \mathrm{NH}_{4} / \mathrm{L}$.

\subsection{Behaviour experiment}

Both the presence of crayfish and the exposure to ammonium nitrate affected to the larval swimming activity. Furthermore, the interaction between the two stressors produced a suggestive effect (Table 2). The tadpoles that had not been exposed to the fertilizer moved more when crayfishes were present; the mean number of times that a line was crossed was $1.70 \pm 0.15$ when the predator was present and $1.33 \pm 0.13$ when it was absent. However, the exposure to $90.3 \mathrm{mg} \mathrm{N}-\mathrm{NO}_{3} \mathrm{NH}_{4} / \mathrm{L}$ inhibited that specific response to the predation risk, and no differences were observed for this vari- 
Table 2

Results of the two-way analyses of the variance (ANOVAs) to test the influence of ammonium nitrate exposure and the presence of a predator (Procambarus clarkii) on two variables indicative of Pelobates cultripes larval behaviour.

\begin{tabular}{|c|c|c|c|c|c|}
\hline Variable & Source of variation & Sum of squares & df & F & $\mathrm{p}$ \\
\hline \multirow[t]{4}{*}{ Line crosses } & Ammonium nitrate & 0.0512 & 1 & 88.630 & $<0.001$ \\
\hline & Predator & 0.0034 & 1 & 5.855 & 0.042 \\
\hline & Interaction & 0.0029 & 1 & 5.097 & 0.054 \\
\hline & Error & 0.0046 & 8 & & \\
\hline \multirow[t]{4}{*}{ Swimming time } & Ammonium nitrate & 0.0427 & 1 & 7.667 & 0.024 \\
\hline & Predator & 0.0028 & 1 & 0.510 & 0.495 \\
\hline & Interaction & 0.0002 & 1 & 0.031 & 0.866 \\
\hline & Error & 0.0446 & 8 & & \\
\hline
\end{tabular}

able between tadpoles checked with or without predator (predator: $0.86 \pm 0.08$; no predator: $0.85 \pm 0.11$ ).

With regard to the swimming time, only the exposure to ammonium nitrate provoked a significant effect, while the presence of crayfishes in the aquaria did not affect this variable (Table 2). Control tadpoles swam during an average time of $15.0 \pm 3.61 \mathrm{~s}$ when crayfishes were not present and of $14.0 \pm 1.32 \mathrm{~s}$ when a predator was present. Tadpoles exposed to the fertilizer showed an average swimming time of $11.5 \pm 2.00 \mathrm{~s}$ in aquaria without crayfish and of $10.5 \pm 1.52$ in aquaria without the predator presence.

\section{Discussion}

Ammonium nitrate is known to produce serious effects on amphibian aquatic stages; environmentally relevant concentrations can be lethal for some species, especially during the most sensitive developmental stages; with regard to the two species tested in the present study Ortiz et al. (2004) recorded almost $60 \%$ of mortality of $\mathrm{D}$. galganoi embryos and early larvae exposed during 15 days to $90.3 \mathrm{mg} \mathrm{N}-\mathrm{NO}_{3} \mathrm{NH}_{4} / \mathrm{L}$. P. cultripes embryos and young tadpoles exposed to the same ammonium nitrate concentration showed $70 \%$ of mortality after 12 days (Ortiz-Santaliestra et al., 2006). These high mortality rates recorded in other studies occurred at concentrations consistent with the maxima expected in freshwaters after the drainage of fertilizers. In this context, EgeaSerrano et al. (2008) reported concentrations of ammonium and nitrate of $120 \mathrm{mg} \mathrm{N}-\mathrm{NH}_{4}{ }^{+} / \mathrm{L}$ and $75.2 \mathrm{mg} \mathrm{N}-\mathrm{NO}_{3}{ }^{-} / \mathrm{L}$, respectively, in watercourses of the Segura River basin (SE Spain).

The low mortality observed during the exposure phase in our experiment is consistent with previous results indicating a high tolerance of free swimming larvae of the two studied species to the same ammonium nitrate levels (Ortiz-Santaliestra et al., 2006). However, sublethal concentrations of ammonium nitrate can also constitute a risk for amphibian tadpoles by indirectly decreasing their survival probabilities. In the present study, we demonstrate how the fertilizer directly increases the risk of P. cultripes tadpoles to be captured by a predator from the same pond of origin. An indirect effect on D. galganoi, related with the reduced larval size of fertilizer-exposed tadpoles, was also observed.

Several studies have reported an increased predation risk of amphibian tadpoles exposed to chemical pollution; for example, larval L. peronii exposed to endosulfan were captured by odonate predators faster than non-exposed tadpoles (Broomhall, 2004). Jung and Jagoe (1995) observed that in a low $\mathrm{pH}$ environment the number of Hyla cinerea tadpoles eaten by larval dragonflies was higher when these tadpoles had been exposed to aluminium. Also, R. catesbeiana tadpoles exposed waters polluted by coal combustion wastes were consumed by predators quicker than those raised in waters from a reference site (Raimondo et al., 1998).

The decrease in predator detection ability might be one of the reasons why exposed tadpoles are more susceptible to predation. Some metals, for example, can interfere with chemical detection of predators in fishes (Hara, 1982). Olfactory detection is the main way of predation risk identification in amphibian tadpoles (Kiesecker et al., 1999; Peacor, 2006), but little is known about how pollutants might impair tadpole chemical detection of predatory risk. In a recent study, Rohr et al. (2009) exposed Bufo americanus tadpoles for 4 days to an environmentally relevant level of atrazine (201 i g/L) known to inhibit chemodetection in fishes. These authors did not find differences between the responses of atrazine-treated and control tadpoles when exposed to several chemical cues, including some predation alarm cues secreted by conspecifics.

Another possible reason why ammonium nitrate might increase larval predation rate is the alteration of their escape behaviour. In our second experiment, we observed that ammonium nitrate produced an overall reduction of the activity of P. cultripes tadpoles regardless of the presence of crayfishes. In the absence of contamination, the greater number of lines crossed when a crayfish was in the aquaria can be interpreted as a strategy to avoid the predator spatially, swimming away from it. Therefore, the reduction in this specific variable provoked by the exposure to ammonium nitrate would indicate a reduction in the escape ability of tadpoles. Larval activity reduction by ammonium nitrate exposure has been found in several studies. For example, Hecnar (1995) observed reduced feeding activity in tadpoles of five anuran species after $24 \mathrm{~h}$ of exposure to $40-100 \mathrm{mg} \mathrm{N}-\mathrm{NO}_{3} \mathrm{NH}_{4} / \mathrm{L}$; tadpoles exposed to ammonium nitrate concentrations $>10 \mathrm{mg} \mathrm{N}-\mathrm{NO}_{3} \mathrm{NH}_{4} / \mathrm{L}$ also exhibited a delayed response to prodding when compared to controls. Activity of larval Bufo bufo exposed to $45.2 \mathrm{mg} \mathrm{N}-\mathrm{NO}_{3} \mathrm{NH}_{4} / \mathrm{L}$ for a minimum of $24 \mathrm{~h}$ was significantly lower than that showed by control tadpoles (Xu and Oldham, 1997).

Pollutant-mediated alterations in behaviour and activity reflect direct toxic effects on nervous and muscular systems. Unfortunately, little is known about this kind of effects in amphibians. Ammonium ion is known to affect the nervous system of many vertebrates by replacing potassium cations at nerve membranes (Randall and Tsui, 2002). In fishes, this mechanism causes Mauthner cell (i.e., giant neurons involved in quick reflex responses) dysfunction, which ultimately provokes an increase in latency to escape from predators (McKenzie et al., 2009). In addition, replacement of potassium by ammonium at the sarcolemmal membrane can cause depolarization of the white muscle (McKenzie et al., 2009), which comprises the major part of axial musculature and is responsible for executing the quick movements involved in the escape response (Sherkov, 1970). Other mechanisms proposed for the deleterious effects of ammonia on the nervous system include alteration of glutamate neurotransmission, direct effects on the GABA A receptor, and alteration of monoaminergic neurotransmitter systems (see review by Ip et al., 2001).

The induction of oxidative stress is another potential neurotoxicity mechanism of both ammonia and nitrate. Ammonia exposure induces the over-activation of $\mathrm{N}$-methyl-d-aspartate type glutamate (NMDA) receptors in neurons (Hermenegildo et al., 2000), which leads to an overproduction of nitric oxide, reactive oxygen species and reactive nitrogen species, resulting in extensive destruction of proteins and oxidation of RNA (Ching et al., 2009). On the other hand, nitrate can be reduced to nitrite, which is transformed into nitric oxide, thus leading to the formation of free radicals such as peroxynitrite, responsible for DNA fragmentation and lipid peroxidation (Pacher et al., 2007).

This reduced activity might be the cause for the faster predation of tadpoles exposed to the fertilizer. However, although a lower activity can lead to an increased predation risk by reducing escape ability (e.g., Lefcort, 1996), it can also be beneficial because inactive tadpoles are more difficult to detect by predators that use primarily visual cues (Lawler, 1989). Nevertheless, the loss of activity can carry additional problems such as poor food search 
efficiency (Anholt et al., 1996; Skelly, 1994), competitive disadvantages (Morin, 1983) and extended developmental time (Skelly, 1994), which ultimately leads to a longer period of potential exposure to predation.

The results of the $\mathrm{D}$. galganoi predation challenge suggest that the faster predation rate on ammonium nitrate exposed tadpoles is related to the smaller size of these tadpoles compared to controls. A number of studies on the effects of inorganic nitrogen on amphibian tadpoles have shown negative effects on growth rates (e.g., Hecnar, 1995; Marco and Ortiz-Santaliestra, 2009; Ortiz et al., 2004; Ortiz-Santaliestra et al., 2006; Xu and Oldham, 1997). The reasons why tadpoles exposed to the fertilizer grew less than controls could include a high energetic investment in detoxification mechanisms (Wright and Wright, 1996), or a decrease of food consumption as part of the toxic effects of the chemical (Egea-Serrano et al., 2009).

The previous studies that have analysed the effects of body size on susceptibility to predation indicate a similar trend to what we have found. The smaller individuals are consumed at a higher rate (Caldwell et al., 1980; Cronin and Travis, 1986). Jung and Jagoe (1995) suggested two hypotheses about the relationship between larval size and predation risk: first, smaller tadpoles would be easier to handle by predators; and second, predators will need a higher number of prey if they are smaller to get a given amount of biomass. These authors observed that the biomass consumed by larval dragonflies, which were used as predators, was similar among the different treatments that they used regardless of individual tadpole size, so they proposed the second hypothesis to explain their results. Our data do not allow us to accept or reject any of the two hypothesis suggested by Jung and Jagoe (1995). Nonetheless, considering the second hypothesis, the higher predation rate of exposed D. galganoi tadpoles because of their small size would be a secondary effect of the ammonium nitrate, which reduces larval growth (Ortiz et al., 2004), thus increasing the individual probabilities of each tadpole to be eaten. A detailed analysis about the reasons underlying the relationship between prey size and predation rate would nevertheless require a different experimental design.

P. cultripes larvae free from the impact of ammonium nitrate swam more when a predator was present in the water than when it was not. However, when tadpoles were exposed to the chemical they always behaved similarly, regardless whether predator was present or absent. In the only previous work which we are aware of that analysed the effect of inorganic nitrogen on larval anti-predatory behaviour, Burgett et al. (2007) did not find an interaction between ammonium nitrate exposure and chemical cues from a mosquitofish on wood frog larval activity. Activity level of tadpoles decreased when exposed to concentrations of ammonium nitrate below $50 \mathrm{mg} \mathrm{NO} \mathrm{NH}_{4} / \mathrm{L}$ as well as when predator cues were added to the water. However, the fertilizer did not alter the specific response of the tadpoles to the predator chemical cues.

We cannot demonstrate whether the absence of a specific response to the predator among ammonium nitrate exposed animals was due to an effect on detection ability or on locomotion. However, even considering a toxicant-mediated impairment of chemodetection, tadpoles would be able to detect crayfishes visually as the behaviour experiment was carried out in small aquaria with totally transparent water. Therefore, we postulate that the ammonium nitrate effect on locomotion was probably the primary reason for the observed results. Altered behavioural responses against predation because of pollution have already been detected in amphibians. Lefcort et al. (1998) demonstrated that some heavy metals reduced the intensity and speed of the escape response in larval R. luteiventris when exposed to predatory fish. Raimondo et al. (1998) also found a lower escape capacity in larval R. catesbeiana exposed to coal combustion wastes, and a similar response was reported by Eroschenko et al. (2002) in A. macrodactylum larvae exposed to the organochlorine pesticide methoxychlor.

An important question to consider when interpreting our results is the high tadpole density, which could have increased the estimates of predation rates during the predation challenges (5-7 tadpoles in 10-L water) and especially of activity levels during the behaviour experiment (10 tadpoles in $3 \mathrm{~L}$ water). In the predation challenges, the high density probably caused a faster consumption of the tadpoles by crayfishes compared to what happens in the field. However, the effects of ammonium nitrate are very consistent and we have no reasons to think that differences among fertilizer concentrations were altered by the density of individuals. In the context of the behaviour experiment, a high density may increase the number of encounters between congeners, thus causing additional stress on animals (Gromko et al., 1973). However, given the short time during which tadpoles swam after the application of the stimulus (15 s as maximum), the number of encounters between congeners was probably very low even in these high density conditions.

Tadpoles of the two species used in the present study are nevertheless accustomed to high densities. To avoid predation by fishes and aquatic invertebrates, D. galganoi lays masses of 300-600 eggs in very swallow waters, only a few centimetres deep, where tadpoles may grow at very high densities (Martínez-Solano, 2009). P. cultripes tends to use larger water bodies, although still very temporary, where strings of several thousand eggs are concentrated in favourable areas of the pond (Recuero, 2010). Therefore, tadpoles are also used to grow at high densities, especially during the initial developmental stages.

\section{Conclusions}

We demonstrate how ammonium nitrate increases the risk of P. cultripes tadpoles to be captured by a predator from the same pond of origin. An indirect effect, as a consequence of the smaller size of the fertilizer-exposed tadpoles, was also observed on larval D. galganoi susceptibility to predation. In addition, we found that the exposure to the chemical impaired the anti-predatory specific behaviour in larval P. cultripes. To the best of our knowledge, this is the first study that demonstrates how nitrogenous fertilizers can affect amphibian larval defensive behaviours, and thereby increase the risk of predation.

Ammonium nitrate is a widely used fertilizer that dissociates quickly into ammonium and nitrate. While we have studied a chemical with a high environmental relevance (large amounts of anthropogenic ammonium nitrate are continuously released to the environment), our experimental design is limited by the difficulties in elucidating the direct toxicity mechanisms because we cannot separate the effects of ammonium, nitrate, and their secondary products (i.e., nitrite, nitric oxide). Further research on this matter is necessary. On the other hand, given that amphibians in the wild are exposed to many different chemicals acting simultaneously (e.g., Mann et al., 2009), future experiments should focus on the analysis of anti-predatory responses in more environmentally realistic scenarios, exposing both predators and prey to cocktails of contaminants or to water samples collected directly from the field.

The impact of environmental pollution on trophic relationships is probably one of its major effects on the normal functioning of ecosystems. Many organisms modify their regular use of the habitat as a response to the predator detection (Petranka et al., 1987). Concentrations of some pollutants low enough to be considered as innocuous from the physiological perspective could affect to this specific anti-predatory behaviour and thus alter the predator-prey relationships or the competitive interactions among different prey (Warner et al., 1966). 


\section{Acknowledgement}

Funding was provided by Regional Government of Castilla y León (Ref. SA071A06) and Ministry of Education and Science of Spain (Ref. CGL2005-0372).

\section{References}

Anholt, B.R., Skelly, D.K., Werner, E.E., 1996. Factors modifying antipredator behavior in larval toads. Herpetologica 52, 301-313.

Babbitt, K.J., Tanner, G.W., 1997. Effects of cover and predator identity on predation of Hyla squirella tadpoles. J. Herpetol. 31, 128-130.

Bridges, C.M., 2002. Tadpoles balance foraging and predator avoidance: effects of predation, pond drying, and hunger. J. Herpetol. 36, 627-634.

Broomhall, S.D., 2004. Egg temperature modifies predator avoidance and the effects of the insecticide endosulfan on tadpoles of an Australian frog. J. Appl. Ecol. 41, 105-113.

Burgett, A.A., Wright, C.D., Smith, G.R., Fortune, D.T., Johnson, S.L., 2007. Impact of ammonium nitrate on wood frog (Rana sylvatica) tadpoles: effects on survivorship and behavior. Herpetol. Conserv. Biol. 2, 29-34.

Caldwell, J.P., Thorp, J.H., Jervey, T.O., 1980. Predator-prey relationship among larval dragonflies, salamanders, and frogs. Oecologia 46, 285-289.

Ching, B.Y., Chew, S.F., Wong, W.P., Ip, Y.K., 2009. Environmental ammonia exposure induces oxidative stress in gills and brain of Boleophthalmus boddarti (mudskipper). Aquat. Toxicol. 95, 203-212.

Cronin, J.T., Travis, J., 1986. Size limited predation on larval Rana areolta (Anura: Ranidae) by two species of backswimmer (Insecta: Hemiptera: Notonectidae). Herpetologica 42, 171-174.

Cruz, M.J., Pascoal, S., Tejedo, M., Rebelo, R., 2006. Predation by an exotic crayfish, Procambarus clarkii, on natterjack toad, Bufo calamita, embryos: its role on the exclusion of this amphibian from its breeding ponds. Copeia 2006, 274-280.

Egea-Serrano, A., Tejedo, M., Torralva, M., 2008. Analysis of the avoidance of nitrogen fertilizers in the water column by juvenile Iberian water frog Pelophylax perezi (Seoane, 1885), in laboratory conditions. Bull. Environ. Toxicol. Chem. 80, $178-183$.

Egea-Serrano, A., Tejedo, M., Torralva, M., 2009. Populational divergence in the impact of three nitrogenous compounds and their combination on larvae of the frog Pelophylax perezi (Seoane, 1885). Chemosphere 76, 869-877.

Eroschenko, V.P., Amstislavsky, S.Y., Schwabel, H., Ingermann, R.L., 2002. Altered behaviors in male mice, male quail, and salamander larvae following early exposures to the estrogenic pesticide methoxychlor. Neurotoxicol. Teratol. 24, 29-36.

Fraker, M.E., 2008. The dynamics of predation risk assessment: responses of anuran larvae to chemical cues of predators. J. Anim. Ecol. 77, 638-645.

Gosner, K.L., 1960. A simplified table for staging anuran embryos and larvae with notes on identification. Herpetologica 16, 183-190.

Gromko, M.H., Mason, F.S., Smith-Gill, S.J., 1973. Analysis of the crowding effects in Rana pipiens tadpoles. J. Exp. Zool. 186, 63-72.

Hara, T.J., 1982. Chemoreception in Fishes. Elsevier, Amsterdam.

Hecnar, S.J., 1995. Acute and chronic toxicity of ammonium nitrate fertilizer to amphibians from Southern Ontario. Environ. Toxicol. Chem. 14, 21312137.

Hermenegildo, C., Monfor, P., Felipo, V., 2000. Activation of Nmethyl-d-aspartate receptors in rat brain in vivo following acute ammonia intoxication: characterization by in vivo brain microdialysis. Hepatology 31, 709-715.

Ip, Y.K., Chew, S.F., Randall, D.J., 2001. Ammonia toxicity, tolerance, and excretion. In: Wright, P.A., Anderson, P.M. (Eds.), Fish Physiology, vol. 20. Academic Press, New York, pp. 109-148.

Jung, R.E., Jagoe, C.H., 1995. Effects of low pH and aluminum on body size, swimming performance, and susceptibility to predation of green tree frog (Hyla cinerea) tadpoles. Can. J. Zool. 73, 2171-2183.

Kats, L.B., Kiesecker, J.M., Chivers, D.P., Blaustein, A.R., 2000. Effects of UV-B radiation on anti-predator behavior in three species of amphibians. Ethology 106, 921-931.

Kiesecker, J.M., Chivers, D.P., Blaustein, A.R., 1996. The use of chemical cues in predator recognition by western toad tadpoles. Anim. Behav. 52, 1237-1245.

Kiesecker, J.M., Skelly, D.K., Beard, K.H., Preisser, E., 1999. Behavioral reduction of infection risk. Proc. Natl. Acad. Sci. 96, 9165-9168.

Lawler, S.P., 1989. Behavioural responses to predators and predation risk in four species of larval anurans. Anim. Behav. 38, 1039-1047.

Lefcort, H., 1996. An adaptive, chemically mediated fright response in tadpoles of the southern leopard frog, Rana utricularia. Copeia 1996, 455-459.

Lefcort, H., Blaustein, A.R., 1995. Disease, predator avoidance, and vulnerability to predation in tadpoles. Oikos 74, 469-474.

Lefcort, H., Maguire, R.A., Wilson, L.H., Ettinger, W.F., 1998. Heavy metals alter the survival, growth, metamorphosis, and antipredatory behavior of Columbia Spotted Frog (Rana luteiventris) tadpoles. Arch. Environ. Contam. Toxicol. 35, 447-456.

Mann, R., Hyne, R.V., Choung, C.B., Wilson, S.P., 2009. Amphibians and agricultural chemicals: review of the risks in a complex environment. Environ. Pollut. 157, 2903-2927.
Marco, A., Ortiz-Santaliestra, M.E., 2009. Pollution: impact of reactive nitrogen on amphibians. In: Heatwole, H., Wilkinson, J.W. (Eds.), Amphibian Biology, Vol. 8, Amphibian Decline: Diseases, Parasites, Maladies and Pollution. Surrey Beatty \& Sons, Baulkham Hills, Australia, pp. 3145-3185.

Martínez-Solano, I., 2009. Sapillo pintojo ibérico-Discoglossus galganoi. In: Salvador, A. (Ed.), Enciclopedia Virtual de los Vertebrados Españoles. Museo Nacional de Ciencias Naturales, Madrid, http://www.vertebradosibericos.org/ (accessed 10.04.10).

McKenzie, D.J., Shingles, A., Claireaux, G., Domenici, P., 2009. Sublethal concentrations of ammonia impair performance of the Teleost fast-start escape response. Physiol. Biochem. Zool. 82, 353-362.

Morin, P.J., 1983. Predation, competition, and the composition of larval anuran guilds. Ecol. Monogr. 53, 119-138.

Ortiz, M.E., Marco, A., Saiz, N., Lizana, M., 2004. Impact of ammonium nitrate on growth and survival of six European amphibians. Arch. Environ. Contam. Toxicol. 47, 234-239.

Ortiz-Santaliestra, M.E., Marco, A., Fernández, M.J., Lizana, M., 2006. Influence of developmental stage on sensitivity to ammonium nitrate of aquatic stages of amphibians. Environ. Toxicol. Chem. 25, 105-111.

Ortiz-Santaliestra, M.E., Fernández-Benéitez, M.J., Lizana, M., Marco, A., 2010. Adaptation to osmotic stress provides protection against ammonium nitrate in Pelophylax perezi embryos. Environ. Pollut. 158, 934-940.

Pacher, P., Beckman, J.S., Liaudet, L., 2007. Nitric oxide and peroxynitrite in health and disease. Physiol. Rev. 87, 315-424.

Parris, M.J., Davis, A., Collins, J.P., 2004. Single-host pathogen effects on mortality and behavioral responses to predators in salamanders (Urodela: Ambystomatidae). Can. J. Zool. 82, 1477-1483.

Peacor, S.D., 2006. Behavioural response of bullfrog tadpoles to chemical cues of predation risk are affected by cue age and water source. Hydrobiologia 573 , 39-44.

Petranka, J.W., Kats, L.B., Sih, A., 1987. Predator-prey interactions among fish and larval amphibians: use of chemical cues to detect predatory fish. Anim. Behav. $35,420-425$.

Raimondo, S.M., Rowe, C.L., Congdon, J.D., 1998. Exposure to coal ash impacts swimming performance and predator avoidance in larval bullfrogs (Rana catesbeiana). J. Herpetol. 32, 289-292.

Randall, D.J., Tsui, T.K.N., 2002. Ammonia toxicity in fish. Mar. Pollut. Bull. 45, 17-23.

Recuero, E., 2010. Sapo de espuelas-Pelobates crultripes. In: Salvador, A., MartínezSolano, I. (Eds.), Enciclopedia Virtual de los Vertebrados Españoles. Museo Nacional de Ciencias Naturales, Madrid, http://www.vertebradosibericos.org/ (accessed 10.04.10).

Relyea, R.A., 2001. The relationship between predation risk and antipredator responses in larval anurans. Ecology 82, 541-554.

Rohr, J.R., Swan, A., Ravel, T.R., Hudson, P.J., 2009. Parasites, info-disruption, and the ecology of fear. Oecologia 159, 447-454.

Schoeppner, N.M., Relyea, R.A., 2005. Damage, digestion, and defence: the roles of alarm cues and kairomones for inducing prey defences. Ecol. Lett. 8, 505-512.

Schoeppner, N.M., Relyea, R.A., 2009. Interpreting the smells of predation: how alarm cues and kairomones induce different prey defences. Funct. Ecol. 23, 1114-1121.

Scholefield, D., Lord, E.I., Rodda, H.J.E., Webb, B., 1996. Estimating peak nitrate concentrations from annual nitrate loads. J. Hydrol. 186, 355-373.

Sherkov, J.K., 1970. Morpho-physiological characterization of peripheral motor apparatus in Salamandra salamandra. J. Evol. Biochem. Physiol. 6, 467-469.

Sih, A., 1992. Prey uncertainty and the balancing of antipredator and feeding needs. Am. Nat. 139, 1052-1069.

Skelly, D.K., 1992. Field evidence for a cost of behavioral antipredator response in a larval amphibian. Ecology 73, 704-708.

Skelly, D.K., 1994. Activity level and the susceptibility of anuran larvae to predation. Anim. Behav. 47, 465-468.

Smith, D.C., 1987. Adult recruitment in chorus frogs: effects of size and date at metamorphosis. Ecology 68, 344-350.

Vedel, N.E., Korsgaard, B., Jensen, F.B., 1998. Isolated and combined exposure to ammonia and nitrite in rainbow trout (Oncorhynchus mykiss): effects on electrolyte status, blood respiratory properties and brain glutamine/glutamate concentrations. Aquat. Toxicol. 41, 325-342.

Verrell, P., 2000. Methoxychlor increases susceptibility to predation in the salamander Ambystoma macrodactylum. Bull. Environ. Contam. Toxicol. 64, 85-92.

Vitousek, P.M., Aber, J., Howarth, R.W., Likens, G.E., Matson, P.A., Schindler, D.W., Schlesinger, W.H., Tilman, D., 1997. Human alteration of the global nitrogen cycle: causes and consequences. Issues Ecol. 1, 1-16.

Warner, R.E., Peterson, K.K., Borgman, L., 1966. Behavioral pathology in fish: a quantitative study of pesticide toxication. J. Appl. Ecol. 3, 223-247.

Wright, P.M., Wright, P.A., 1996. Nitrogen metabolism and excretion in bullfrog (Rana catesbeiana) tadpoles and adults exposed to elevated environmental ammonia levels. Physiol. Zool. 69, 1057-1078.

Xu, Q., Oldham, R.S., 1997. Lethal and sublethal effects of nitrogen fertilizer ammonium nitrate on common toad (Bufo bufo) tadpoles. Arch. Environ. Contam. Toxicol. 32, 298-303.

Yovanovich, C.A.M., Jungblut, L.D., Heer, T., Pozzi, A.G., Paz, D.A., 2009. Amphibian larvae and zinc sulphate: a suitable model to study the role of brain-derived neurotrophic factor (BNDF) in the neuronal turnover of the olfactory epithelium. Cell Tissue Res. 336, 1-9. 